\title{
ONLINE SPREAD AND PATIENT CONTRIBUTIONTO THE IMPROVEMENT OF A SYSTEMIC SCLEROSIS PATIENT EDUCATION HANDOUT DURING THE PANDEMIC OF COVID-19
}

Caio Carvalhais Chaves ${ }^{1, *}$, João Victor de Pinho Costa ${ }^{1}$, Anderson Ramos Lisboa ${ }^{1}$, Ana Leticia Fontes de Oliveira Marcelino ${ }^{1}$, Urias Paulo Furquim Junior ${ }^{2}$, Tamires Rodrigues Pimentel da Silva ${ }^{1}$, Vivian Guerra de Faria ${ }^{1}$, Laura Cristine Carmo da Silva ${ }^{1}$, Liliane Morais Amaral ${ }^{1}$, Junia Amorim Andrade ${ }^{1}$, Gilda Aparecida Ferreira ${ }^{1}$, Adriana Maria Kakehasi ${ }^{1}$, Ricardo Cruz Lage $^{1}$, Maria Raquel da Costa Pinto ${ }^{1}$, Maria Fernanda Brandao Resende Guimarães ${ }^{1}$, Flavia Patrícia Sena Teixeira Santos ${ }^{1}$, Leandro Augusto Tanure $^{1}$, Débora Cerqueira Calderaro ${ }^{1}$

1. Universidade Federal de Minas Gerais, Belo Horizonte (MG), Brazil. 2.Universidade Estadual do Rio de Janeiro, Rio de Janeiro (RJ), Brazil. *Corresponding author: caiocarvalhaischaves@gmail.com

\section{BACKGROUND}

Systemic sclerosis (SSc) is a rare autoimmune disease of the connective tissue, mainly characterized by excessive deposition of collagen in the skin and multiple internal organs. The hands are frequently compromised, mainly by Raynaud's phenomenon and scleroderma. To prevent and minimize these changes, drug treatment, rehabilitation, and patient education (PE) are essential, including guidance on the nature of SSc and hand care techniques. In this sense, the production and distribution of educational materials, such as patient education handouts, serve as adjuncts to PE.

\section{MATERIALS AND METHODS}

Based on the university hospital patients' doubts regarding self-care in SSc, a search of the scientific literature was carried out and a patient education handout was elaborated, explaining definitions of medical terms regarding SSc, such as scleroderma, Raynaud's phenomenon, and calcinosis, as well as addressing hand care techniques to prevent functional loss and complications. With social distancing imposed by the COVID-19 pandemic, an online version of the handout was released on the university website and social networks. Evaluation of the handout by 33 SSc patients, addressing the understanding of the text and illustrations, and a score (0-10) for the aesthetics, relevance, and explicitness was undertaken.

\section{RESULTS}

The online release of the handout increased its scope since it reached around 5,700 people. Of 33 patients evaluating the digital handout, none reported difficulties with the text and $87.9 \%$ reported no difficulties with the illustrations. They suggested the addition of new issues and the improvement of some illustrations. The scores given by the respondents to the patient education handout were very satisfactory, with an average of 9.21 ( $S D \pm 0.80$ ) for aesthetics; 9.30 ( $S D \pm 0.85$ ) for relevance and 9.57 (SD \pm 0.63 ) for explicitness. After examining the responses, the handout was modified and a new version (Figs. 1-6) was developed and published on social networks. Patients addressing the new version of the handout commented on its improvement. 


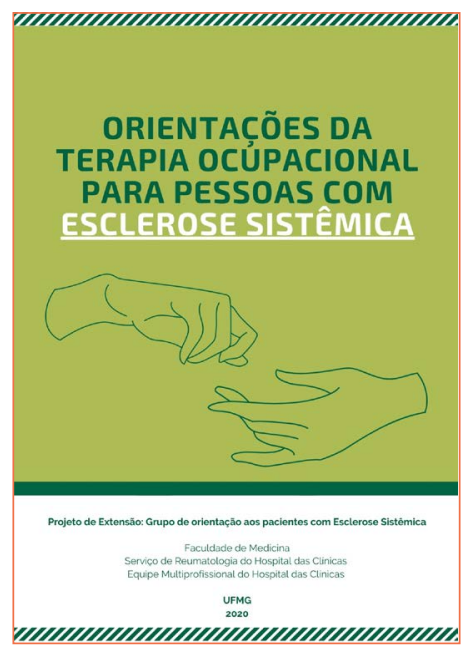

Figure 1. Cover of the patient education handout.

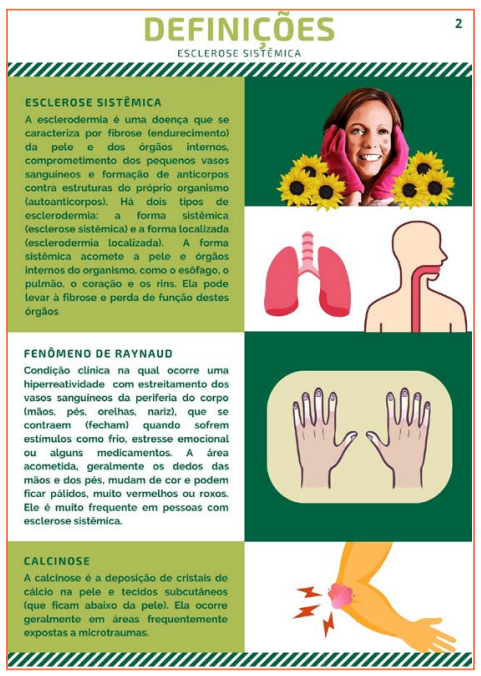

Figure 2. Page 2 of the patient education handout.

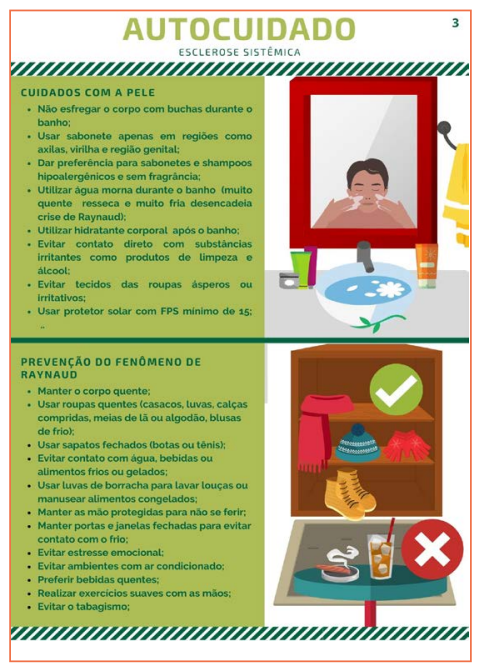

Figure 3. Page 3 of the patient education handout. 


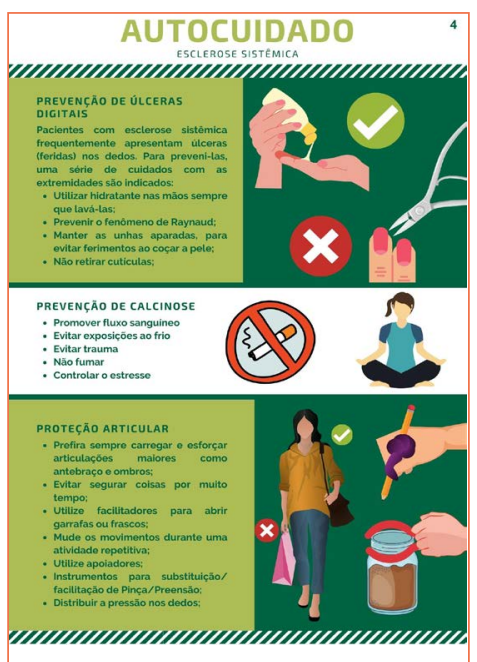

Figure 4. Page 4 of the patient education handout.

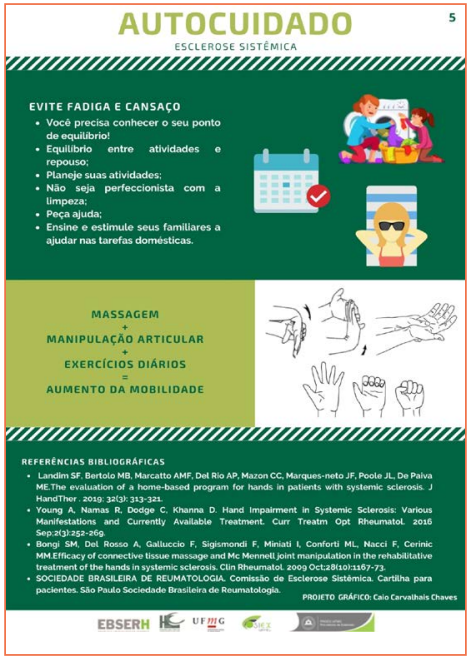

Figure 5. Page 5 of the patient education handout.

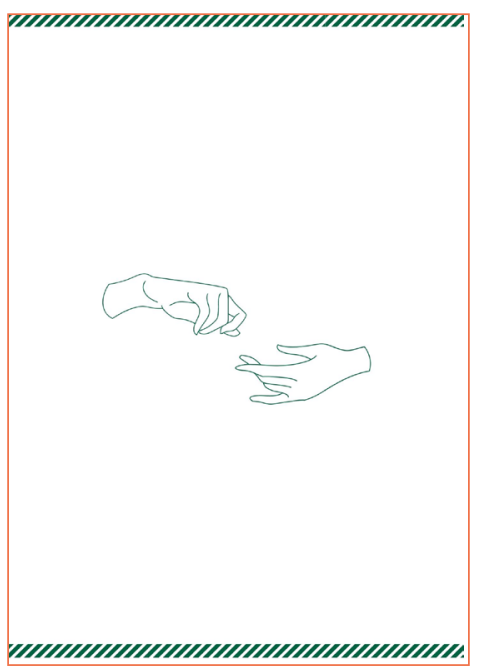

Figure 6. Back cover of the patient education handout. 


\section{CONCLUSION}

The development of educational materials for patients with SSc is relevant, since they provide reliable information about this disease and hand care techniques, solving doubts, and preventing functional losses. The participation of patients in the development of educational materials may improve their understanding. With social distancing, the online distribution of the handout is expanding its scope. Given the good acceptance of patients, we believe that the objectives of this educational material have been achieved.

\section{ACKNOWLEDEGMENTS}

We thank the multidisciplinary team at the Hospital das Clínicas from Universidade Federal de Minas Gerais (EBSERH/HC-UFMG) for their support.

\section{REFERENCES}

Landim SF, Bertolo MB, Abreu MFM, Del Rio AP, Mazon CC, Marques-Neto JF, et al. The evaluation of a home-based program for hands in patients with systemic sclerosis. J Hand Ther. 2019; 32(3): 313-21. https://doi.org/10.1016/j.jht.2017.10.013

Young A, Namas R, Dodge C, Khanna D. Hand impairment in systemic sclerosis: various manifestations and currently available treatment. Curr Treatm Opt Rheumatol. 2016;2(3):252-69. https://doi.org/10.1007/s40674-016-0052-9

Bongi SM, Del Rosso A, Galluccio F, Sigismondi F, Miniati I, Conforti ML, et al. Efficacy of connective tissue massage and McMennell joint manipulation in the rehabilitative treatment of the hands in systemic sclerosis. Clin Rheumatol. 2009;28(10):1167-73. https://doi.org/10.1007/ s10067-009-1216-x

[SBR] Sociedade Brasileira de Reumatologia. Cartilha de Esclerose Sistêmica. São Paulo: SBR, 2020. 